\title{
The Histamine Test as an aid in the Diagnosis of Early Leprosy.
}

\author{
Jose Rodriguez and Fidel C. Piantilla.
}

I $\mathrm{T}$ is generally agreed that one of the greatest needs in leprosy work to-day is a reliable serological test which can be depended upon to detect the disease even in its earliest stages. Unfortunately, in spite of claims of some to the contrary, such a test does not yet exist. Until one has been claborated, and since in the "incipient stage" the presence of M. Lepræ cannot usually be demonstrated on ordinary methods of making the bacteriological examination, we have to depend almost entirely on clinical methods such as the detection of the anæsthesia, palpation of thickened nerves and superficial glands, careful history-taking, examination of the external lesions as to appearance, location, etc., in order to arrive at a diagnosis in this stage. Naturally, the accuracy of the diagnosis must depend considerably on the experience of the physician making the diagnosis. The introduction, therefore, of any clinical test which will tend to minimise the influence of the personal equation should prove of value.

We believe that we have found such a test in the socalled " Histamine Test." When a dilute solution of histamine is pricked into the normal skin, a reaction takes place, starting in about 20 seconds with the appearance of a circular sharply defined local reddening surrounding the prick, and measuring, when fully developed, from 3 to $4 \mathrm{~mm}$. in diameter. This is followed in another 15 to 30 seconds by a flush or flare which appears on the surrounding skin. It is of utmost importance to distinguish this flare from the local red reaction. The flare is of dark red or scarlet colour, contrasting with the brighter shade of the latter; it has diffused and often crenated borders which may extend from 2 to $3 \mathrm{~cm}$. from the centre of the reaction. Soon after the appearance of the flare, a discreet wheal forms at the site of the prick; this is generally at its maximum development in 3 to 5 minutes, at which time it measures from 3 to $4 \mathrm{~mm}$. in diameter and about 1 to $2 \mathrm{~mm}$. in height. The wheal usually occupies the area originally covered by the local red reaction although in many cases the two do not coincide, the wheal being usually smaller than the localised red area.

The full reaction of the normal skin to histamine, consisting of the local redness or vasodilation, the flare, and the 
edema or wheal has been called by Lewis the "triple response." Lewis has demonstrated that the triple response is a characteristic reaction of the normal skin following injury inflicted by such agents as heavy stroking, pricking, scratching, freezing, heating, electrical shocks, as well as by the introduction of irritant substances such as acids, alkalies, mustard oil, cantharidid, nettle sting, morphine, etc. Ultra-violet rays, ordinary sunlight, X-ray and radium emanations, bacterial poisons, certain chemicals such as dichloræthyl sulphide, etc., give rise to more slowly developing reactions. He has also proved that the local redness and the wheal or edema is due to direct action of the injury or irritant on the capillaries, while the flare is produced by the dilatation of the arched arterioles and is reflex in nature, being dependent upon the integrity of the cutaneous nerves. The arteriolar dilatation is mediated through a purely local nervous reflex and does not depend upon a spinal reflex arc.

This test has been tried by Lewis and his colleagues ${ }^{2}$ on anæsthetic skin to which the sensory nerves have been cut surgically or interrupted by injection of anæsthetics. When the interruption produced surgically or by anæsthesia is recent, the reaction to the histamine test is complete in all its details, although the skin has already been rendered anæsthetic. But if sufficient time (six to fifteen days) is allowed for the nerve to degenerate or if the skin is anæsthetised locally, the flare is lost. Under the circumstances, the local red reaction and the edema appear as in the normal reaction of the skin.

Thus, the loss of the flare following a histamine test is a sign of degeneration of the sensory nerves supplying the skin tested, and possibly also of direct involvement of the nerve endings as in local anæsthesia.

Histamine or B-iminazolylethylamine is described by Lewis as "the amine produced when carbon dioxide is split from histidine, a substance occurring naturally in the body and a protein derivative." It was extracted by Barger and Dale ${ }^{3}$ from the intestinal mucosa, and was later thoroughly studied by Dale and Laidlaw. The histamine test as applied to the skin was first reported by Eppingers, and later elaborated by Sollman and Pilcher ${ }^{6}$ and by Lewis and Grant?

\section{The test.}

In most of our tests, we have used a 1/1,000 dilution of the phosphate in normal salt solution. With stronge 
solutions, a larger flare is occasionally obtained, but the reactions are not as constant as with the 1/1,000 solution.

A small drop of the solution is carefully placed within the suspicious macule to be tested, and another is dropped on normal skin at least 1-in. away from the border of the lesion for control. With a sharp pin, a prick is made through the drop into the skin underneath, taking care to exert just sufficient pressure to drive the point through the epidermis without causing any bleeding. The histamine solution is wiped off immediately and the pricks are closely observed under good, natural light.

The test is said to be negative when the complete response is elicited and positive when the flare is absent.

There are some individuals on whom the reaction is diminished : in a few, the flare is so faint as to be practically absent. When the response is weak and the skin tested is on an extremity, the flare may be brought out to its maximum extent and intensity by previously congesting the extremity with the help of a broad rubber band or the pneumatic cuff of a blood pressure apparatus.

Finally, it must be recognised that the reaction is harder to elicit on the dark skin of a Filipino than on white skin.

Result of the Histamine Test in Leprosy. In the pale macule.

The flush is always absent in the depigmented macule of leprosy. When the histamine prick is made just outside the border, a flare develops on the normal skin but stops sharply at the border and does not extend into the macule. When the prick is made just inside the border, the flare is prevented from appearing even on the bordering normal skin.

A word of caution must be given at this point. The flare generally masks the local redness following the histamine test on the normal skin. When the flare is abolished as in leprous macules, the local redness becomes prominent and may be mistaken for the flare by the beginner. The area of local redness is sharply localised, circular in shape, bright red or pink in colour, extending at the most 2 or $3 \mathrm{~mm}$. beyond the wheal, and tends to become cyanotic before fading. On the other hand, the flare is not definitely localised, the size is usually about 3 to $4 \mathrm{~cm}$. in diameter, irregular in shape although it tends to be oblong with its long axis along the length of the member, and the colour is dark red. On fading, the flare becomes speckled but the colour remains the same from beginning to end. 
The wheal in the macule is usually of the same size as that on the normal skin. Sometimes, the edema may be less ; at other times, the wheal develops faster in the macule, reaching its full development in two minutes while the wheal on the control skin is at its height in 3 to 5 minutes. The ultimate size, however, is almost the same.

The test has been applied on the macules of T. Flava and other types of pale-looking pityriases, on leucoderma, old scars, fading psoriasis lesions, etc., which may be mistaken for the pale macule of leprosy. In every case, the flare is present provided the individual is not unsusceptible to histamine, in which case, the flare is also diminished or absent on the normal skin.

\section{In the reddish macule.}

When the redness of the lesion is marked, only the wheal may be elicited, but when the colour is not so striking, the local redness may be scen.

When hyperesthesia is present, as is usually the case when the lesion is bacteriologically positive, the flare is not constant. In a few macules, the flare is present; in the majority of the cases it is absent. If there is accompanying infiltration or edema so that the skin looks tense, glistening, and bright red in colour, the wheal is apt to be slight or absent.

Ths histamine test was tried in cases of dermatitis from various causes, active psoriasis lesions, tinea circinata and other ringworm infections, fresh scars and other lesions which may similate the red macule. When the inflammation in such lesions is active and there is considerable redness, the wheal is generally diminished or even absent while the flare is present, manifested by increased redness of the skin. It must be stated that when the redness of the original lesion is at all bright, it is next to impossible to distinguish the flare. When this is the case, the best way to perform the test is to prick the histamine solution just inside the border. In the non-leprotic lesion, the flare appears on the adjacent portion of the skin outside the border, whereas there is no such flare extending from the macule in early leprosy.

REFERENCES.

ILewis, T. The Blood Vessels of the Human Skin and their Responses. Shaw \& Suns Ltd. London, 1927. 47.

albid. p. 69-70.

8Barger, G., and Dale, H. H. B-iminazolylethylamine a Depressor Constituent of Intestinal Mucosa. Journ. of Physiol., 1910-11, xli. 499-503.

-Dale, H. H., and Laidlaw, P. P. The Physiological Action of B-iminazolylethyla. minc. Jouyx. of Physiol., 1910-11, dji. 318-344. 
Ibid. Further Observations on the Action of B-iminazolylethylamine. Jou'n. of Physiol., 1911-1912, xliii, 182-195.

5Eppinger, $H$. Uber eine eigentumliche Hautreaktion, hervorgerufen durch Ergamin . Wein. med. Wochenschr., 1913, lxiii, 1414.

oSollman, I., and Pilcher, J. D., Endermic Reactions. Journ. of Pharmacol and eper. Therap., 1917, ix, 309-340.

7Lewis, I., and Grant, R. T., Vascular Reactions of the Skin to Injury. l'art II, Heart, 1924, xi, 209-265. 